Please do not remove this page

RMIT

UNIVERSITY

\title{
Rethinking international TV flows research in the age of Netflix
}

Lobato, Ramon

https://researchrepository.rmit.edu.au/esploro/outputs/9921861731601341/filesAndLinks?institution=61RMIT_INST\&index=null

Lobato, R. (2018). Rethinking international TV flows research in the age of Netflix. Television and New Media, 19(3), 241-256. https://doi.org/10.1177/1527476417708245

Document Version: Published Version

Published Version: https://doi.org/10.1177/1527476417708245

Repository homepage: https://researchrepository.rmit.edu.au

(c) The Author(s) 2017

Downloaded On 2023/04/26 22:19:13 +1000

Please do not remove this page 
Thank you for downloading this document from the RMIT Research Repository.

The RMIT Research Repository is an open access database showcasing the research outputs of RMIT University researchers.

RMIT Research Repository: http://researchbank.rmit.edu.au/

\section{Citation:}

Lobato, R 2018, 'Rethinking international TV flows research in the age of Netflix', Television and New Media, vol. 19, no. 3, pp. 241-256.

See this record in the RMIT Research Repository at:

https://researchbank.rmit.edu.au/view/rmit:47083

Version: Published Version

Copyright Statement:

(c) The Author(s) 2017.

Link to Published Version:

https://dx.doi.org/10.1177/1527476417708245 


\title{
Rethinking International TV Flows Research in the Age of Netflix
}

Television \& New Media 2018, Vol. 19(3) 24I-256

(C) The Author(s) 2017

Reprints and permissions: sagepub.com/journalsPermissions.nav DOI: I0.II77/I5274764I7708245 journals.sagepub.com/home/tvn

@SAGE

\section{Ramon Lobato'}

\begin{abstract}
This article considers how established methodologies for researching television distribution can be adapted for subscription video-on-demand (SVOD) services. Specifically, I identify a number of critical questions-some old, some new-that can be investigated by looking closely at SVOD catalogs in different countries. Using Netflix as an example, and drawing parallels with earlier studies of broadcast and cinema schedules, I ask what Netflix's international catalogs can tell us about content diversity within streaming services, and how this can be connected to longer traditions of debate about the direction and intensity of global media flows. Finally, I describe what a research agenda around Netflix catalogs might look like, and assess the utility of various kinds of data within such a project (as well as some methodological pitfalls).
\end{abstract}

\section{Keywords}

Netflix, subscription video-on-demand (SVOD), streaming, digital distribution, research methods, global television

As video streaming services proliferate and evolve, the logic of television distribution is changing. Users of streaming services - especially subscription video-on-demand (SVOD) platforms such as Netflix, Hulu, and Amazon Prime Video-have become accustomed to a distinctive way of watching TV, characterized by interactive, à la carte selection from algorithmically curated catalogs of content. As any Netflix subscriber knows, the way platforms present and filter content is fundamentally distinct from the flow of linear broadcasting. Television is acquiring - unevenly, but substantively - a database form.

\section{'RMIT University, Melbourne, Australia}

\section{Corresponding Author:}

Ramon Lobato, RMIT University, I24 La Trobe Street, Melbourne, VIC 3000, Australia.

Email: ramon.lobato@rmit.edu.au 
Scholars including Tryon $(2013)$ and Lotz $(2014,2017)$ have begun to trace the outlines and effects of this structural change. Lotz $(2017,2)$ identifies the "personalized delivery of content independent from a schedule" as one of the defining features of "nonlinear" television, and argues that it represents a wider transformation in the logic of television industries from scheduling to curation. She also suggests that "parallels to the rich insight available about scheduling strategies must now be created for commercial library curation," which is "by and large untheorized" (Lotz 2017, 8).

Understanding curation, filtering, catalogs, and other phenomena associated with Internet TV services represents a challenge for television studies, and it requires some reflection on the sources and methods we use in our work. What is involved in studying a platform as opposed to a channel? How can we analyze the programming available on a particular platform, or across a number of platforms? How might we critically assess the levels of content diversity on platforms (including the kinds of content available and the national origin of that content)? To what extent does a platform's content offering differ between countries, and how should we account for this?

In this article, I want to clarify one part of this problem, by looking closely at some research possibilities and practicalities concerning SVOD catalogs. By catalog, I mean the corpus of licensed or owned content distributed by a particular platform at a given time. In the case of SVOD services such as Netflix, Hulu, and Amazon Prime, catalogs are essentially "revolving collections of licensing agreements" (Hoyt 2014, 200) which change over time and across space, posing a number of research challenges. ${ }^{1}$ My central claim is that as television studies moves further into the Internet age, it must develop a robust understanding of how catalogs work if it wishes to understand wider dynamics of access, choice, and diversity in digital distribution.

The article begins by discussing the history of TV schedule research and its potential application to SVOD. I then use the example of Netflix to show how a catalog can be studied using both official and unofficial sources. Next, I review some recent empirical research on Netflix and assess what can be learned from these experiments. Finally, I propose a number of critical questions for future research in this area, along with some practical "dos and don'ts." The overall argument here is that Netflix and other SVOD services present both new and old questions for television research, and thus require a combination of existing and emergent methodologies.

\section{From Schedule to Catalog}

In considering the challenges of studying platforms, it is worth bearing in mind the history of TV programming research. Since the earliest years of television studiesbeginning perhaps with Raymond Williams' ([1974] 2003, 77-120) famous analysis of a week's worth of TV in the United Kingdom and the United States - scholars have relied on TV schedules as an index of broadcast distribution. By scouring TV schedules published in metropolitan, regional, or national newspapers, it has been possible to reconstruct the range of linear content available to TV audiences and to gain insight into the programming logics of television institutions. In this way, schedules have 
provided a basis for structured content analysis around particular issues, such as the amount of imported material or the genre mix of prime-time programming.

Consider two major TV research projects from the 1970s: Broadcasting in the Third World (Katz and Wedell 1978) and the UNESCO report Television Traffic-A One-Way Street? (Nordenstreng and Varis 1974). These famous studies both used TV schedules, along with various other sources, to establish an evidence base about the origin and direction of cross-border flows. ${ }^{2}$ While raising tricky definitional issues when it came to determining the national origin of coproductions or news programs with inserted material (Nordenstreng and Varis 1974, 11), this approach provided an empirical basis for strong claims about international television trade- such as Nordenstreng's and Varis' claim of a one-way, West-to-rest pattern (i.e., the cultural imperialism thesis). Although this argument was revised in later work, which questioned both the direction of such flows and the implied relationship between distribution and reception (Liebes and Katz 1990; Sinclair et al. 1995), for our purposes, it is enough to note the use of TV schedules here and the way this data source helped to shape a larger critical paradigm.

In the United States, a related tradition of communications policy research has used TV schedules to measure trends in TV programming, in terms of the prevalence of certain program types, genres, production sources/contexts, or specific textual attributes. Litman (1979), for example, used listings in TV Guide as a basis for understanding program-type diversity in U.S. network television. ${ }^{3}$ One could also include here a parallel tradition of cinema history research that uses movie showtime data to understand exhibition dynamics (Sedgwick 2000; Verhoeven et al. 2016). Broadly, the objective of these various research approaches was to measure flows of scheduled screen content either within or and across nations.

Schedules are obviously different from catalogs in that the former are linear sequences of programmed content and the latter are interactive, curated databases. But the two objects are comparable in the sense that both index the range of content available through a particular distribution system, and thus delimit-without determining - the likely range of textual experiences available to audiences through that system. Furthermore, SVOD catalog research has the advantage of being automatable and scalable, unlike earlier schedule analysis which required manual data entry and coding. So there are opportunities here to extend TV research traditions to encompass new digital services, while keeping in mind the overarching intellectual questions of TV flows research as a critical project concerned with understanding levels of media diversity, choice, and access. However, such research must be carefully designed to account for the structural specificities of platforms, hence the need for methodological reflection.

Given the popularity of SVOD services, especially Netflix, it seems important to analyze SVOD programming with the same critical intent that we have previously applied to broadcast programming (though not necessarily with the same methods). In certain markets, especially Canada, United Kingdom, Australia, New Zealand, and parts of Western Europe, Netflix is now a mainstream media service competing with broadcast and cable TV. Yet it is not (yet) subject to the same kinds of regulation, 
including local content quotas, that apply to those incumbents. ${ }^{4}$ Following Nordenstreng and Varis, perhaps research on Netflix and other platforms might want to look more closely at the national origin of content within the platform and what this means for long-standing debates about TV flows, cultural imperialism, and cultural synchronization. How "local" is Netflix programming? Does American content uniformly dominate? Do older arguments about one-way flow and "wall-to-wall Dallas" (CBS, 1978-1991) still apply in the age of Internet TV? The answers to these and other questions lie in the structure and contents of the catalog, to which I now turn.

\section{Understanding the Netflix Catalog System}

For the rest of the article, I want to use the Netflix catalog as an example to explore some of these issues. It should be emphasized that Netflix is not a typical case, for each platform has its own specificity. For example, catch-up services and studio-portals (e.g., CBS All Access) tend to operate as "a vertical extension of self-owned creative goods" (Lotz 2017, 40), offering a bounded selection of mostly owned and exclusively licensed content. At the other end of the spectrum, there is YouTube, a hybrid free/ subscription/transactional service in which professional and amateur content comingle and are not easily distinguished. In the case of the catch-up services, it is relatively simple to view the overall catalog through lists and "browse" functions. This is harder to do for SVOD platforms (which are heavily filtered via algorithmic recommendations) and impossible for YouTube. So the idea of a catalog varies considerably across these services. It is also important to emphasize that Netflix, while the most established of the multi-territory SVOD services, is by no means popular or even significant in every country; its success has been highly uneven. So discussions of global SVOD must go beyond Netflix. Nonetheless, for the kind of research proposed here-involving comparison across a single platform-Netflix is a good case to work with, as its catalogs have a defined structure that makes them amenable to comparative research, and there is enough complexity and difference within the platform to make the effort worthwhile.

Netflix catalogs are composed of a finite number of "viewables", or units of content. Most of these are licensed from other networks and producers. Netflix's heavy investment in original production since 2011 means that original productions such as House of Cards (2013-) make up a fast-growing proportion of Netflix catalogs; but originals still account for less than a quarter of the overall catalog in most territories (Veed Analytics 2016). In other words, Netflix still relies on licensed content, and will do so for the foreseeable future at least. As licensing agreements come into effect and expire, content is constantly moving through the Netflix system. We can therefore say that Netflix catalogs are temporally differentiated, because they are constantly changing, and also spatially differentiated, because users in different countries experience different ranges of content.

It is important to note the history of Netflix's global operations here. Since 2010, Netflix has been an aggressively international service, expanding first to Canada in 2010, then to Latin America, Western Europe, and parts of Asia over the next few 
years, before switching on in all remaining countries (except China, Crimea, North Korea, and Syria) in January 2016. One implication of this internationalization is that it is no longer feasible to speak of "a" single Netflix, understood as a service offering the same content and the same experience everywhere; it is now more accurate to describe Netflix a series of national services linked through a common platform architecture. Roughly half of Netflix's 100 million global subscribers now live outside the United States, and this number is climbing. As its global user base grows relative to its domestic audience, Netflix may become even more differentiated in its programming, calling into question the coherence of the Netflix phenomenon as it moves from a national to a global scale. This means that catalog analysis must usually be conducted with reference to specific territories rather than across the whole platform.

This qualification noted, let us now look in more detail at methods for accessing catalog data. Netflix does not publish its catalogs, but the information can be assembled in a roundabout way using data and metadata from the platform. To learn more about a particular video, we can visit its unique URL (e.g., netflix.com/browse?jbv=70285368 takes us to the landing page for the licensed Danish drama Rita). Here, we find a variety of information presented in a standardized, extractable format, including title, creator, cast, age-rating, duration, genres, attributes ("suspenseful," "provocative"), user reviews, and user star ratings. With a bit more digging, we can also identify the territories in which the video is available, the languages into which it has been dubbed or subtitled, and the expiry date of its license. Some of these data can be manually copied and pasted; alternatively, one can use a webcrawler script that pings each active URL on the Netflix domain, extracts the relevant metadata, and then moves onto the next active URL. In this way, a detailed index of the Netflix catalog in any given territory can be constructed. A third, simpler option is to use an unofficial comparator website such as Unogs (Unofficial Netflix Online Global Search), Allflicks, or Netflixable, which make Netflix's international catalog data available in an easy-to-use format. These sites are now routinely used by researchers as proxies for the Netflix catalogs (see below). Unogs also supplies these data to other interested parties via a subscription API (application programming interface).

What can be done with this catalog data - and what might it tell us? For starters, we can compare the size of different Netflix catalogs around the world. At the time of writing, the largest catalogs are the United States (5,169 titles), Guadeloupe $(4,959)$, Martinique (4,957), French Guiana $(4,867)$, and Montserrat $(4,727)$. The smallest catalogs are in Zambia (1,295), Sudan (1,399), Western Sahara $(1,436)$, Comoros $(1,442)$, and Eritrea $(1,443)$. These data tell us something about the relative strategic importance for Netflix of different territorial markets. Unsurprisingly, the United States has the largest catalog: it is Netflix's home and its most significant and profitable market. In contrast, African nations languish at the bottom of the scale. These are markets in which Netflix does not wish to actively compete, and in which its SVOD model is poorly aligned with people's viewing habits and income levels.

In between these extremes, there are some interesting stories. For example, why do Caribbean countries have the next largest catalogs after the United States? This does not reflect the strategic importance of the Caribbean market but is more likely to be a 
side-effect of licensing deals that lump in the Caribbean with the United States. It is also worth noting the relatively large size of Latin American catalogs, which have over 4,000 titles each. This reflects both the longer engagement Netflix has had with these markets (Latin America was the first destination after Canada in Netflix's international expansion) as well as the regional licensing dynamics of Spanish-language media.

Very few countries in the Unogs list have exactly the same number of viewables, even when they are in the same region. For example, Martinique has 4,957, Guadeloupe has 4,959, and French Guiana has 4,867. This suggests that suppliers still follow slightly different maps of the world when making their content available to platforms. It also calls into question Netflix's claims that it is pushing toward a fully global licensing paradigm in its licensing negotiations with suppliers. Although there is some evidence of a bargain-bin collection of material that has been licensed across a high number of markets (this appears to form the basis for many Netflix catalogs in thirdworld markets where the company has not made an effort to license local or regional content), even this widely licensed batch viewables are still not always licensed for all territories. Looking through Unogs' data on the number of licensed territories for each viewable, we can see the number jump around without any consistency-from 132, to 164 , to 175 , and so on. Contractual contingencies like this are a striking feature of the international Netflix ecology. They suggest, despite claims to the contrary, that the audiovisual licensing system remains strongly territorial.

There are obvious issues with using catalog-size data for research purposes. Catalogs are by nature ephemeral: licensing deals change constantly as content comes online and expires. A longitudinal approach would therefore be required to make this a meaningful exercise. ${ }^{5}$ Another limitation of catalog-size data is that it does not tell us anything about the quality, cost, or value of the videos in question. So we must be careful in how we use catalog-size data; without analysis and contextualization of the viewables in question, its research utility is limited.

\section{From Size to Diversity: How “American” Is Netflix Programming?}

To take our analysis further, the next step would be to examine the characteristics of the videos within national catalogs, which calls for a more complex methodology that can cross-reference Netflix with other sources. With this in mind, let us now consider some recent empirical research on the national origin of film and TV content within Netflix. Such research typically asks, how "local," or how "American," is the Netflix catalog in a given country - and what does this mean for access to local film and television? This is a very contentious issue, which relates directly to ongoing policy debates about cultural diversity, cultural imperialism, and local content. Hence, the nature and methodology of such research requires careful consideration.

An early study in this vein was the report by Miller and Rudniski (2012) for the Canadian Radio-Television and Telecommunications Commission, which found that only 3 percent of feature films and 14 percent of TV content in the Canadian Netflix catalog were Canadian. More recently, the European Audiovisual Observatory has 
produced two fascinating reports on this issue, Origin of Films in VOD Catalogs in the EU (Ene and Grece 2015) and Origin of Films and TV Content in the EU (Fontaine and Grece 2016). Developed in response to ongoing policy debates within the European Union about cultural and linguistic diversity, the Observatory research provides a richly textured account of diversity dynamics within European VOD and SVOD services. These are multi-platform rather than single-platform studies, which look at Netflix alongside iTunes, Microsoft Movies, and a range of national services. ${ }^{6}$ Their aim is to identify which films and TV shows were available in each catalog, and thus to establish the proportion of EU-originated content as well as the proportion of locally produced content (e.g. how much Italian content in the Italian catalog). In this way, Observatory researchers can assess the degree to which different VOD and SVOD services make an attempt to license local content for the different territories in which they operate, or rely instead on a mostly Hollywood cinema offering.

The most recent Observatory findings suggest that, across Netflix's 28 European catalogs, Hollywood movies typically account for over two thirds of the titles on offer. EU-originated movies, in contrast, make up between 12 percent and 21 percent of the catalog, depending on the market. The proportion of local movies varied between 0 percent and 10 percent. In most EU28 countries (including Austria, Bulgaria, Cyprus, the Czech Republic, Estonia, Finland, Greece, Croatia, Hungary, Lithuania, Latvia, Malta, Romania, Slovenia and the Slovak Republic) there were no local films available at all. The range of television content on Netflix is somewhat more localized than movies: approximately half the TV titles in each catalog are American, and around a third are European, with a bit of variation between national catalogs. British, French, and German TV content is well represented in certain markets, but programming from smaller European countries is largely absent (Fontaine and Grece 2016).

The Observatory reports are considerably more complex than any of the aforementioned catalog-size rankings because they involve not only scraping Netflix data but also matching these data against various other databases. They also offer a useful methodology for measuring diversity across services - thus providing a basis for understanding the regional SVOD ecology, as well as the contents of any single service. In addition, they are able to do a number of other things, such as measuring the degree of overlap between services (by distinguishing between unique and cumulative titles), and capturing the relationship between new-release and back-catalog content (via cross-referencing year of production). These methods are all replicable and are well documented in the reports.

The key finding from the Observatory studies - that Hollywood movies are dominant on SVOD services, and especially on Netflix - may not come as a surprise to scholars of international media. But such research is nonetheless significant because it provides an empirical basis for assessing claims and concerns about U.S. domination in digital media channels. These concerns are important for international media policy generally, but are especially acute in the European Union. Given that, as of 2016, the European Commission's revised 2016 Audiovisual Media Services Directive proposes a 20 percent minimum European content quota on all streaming services - including U.S.-based services like Netflix and Amazon-the findings of such research do not 
appear to have gone unnoticed by policy makers. This signals a potential area of policy impact for SVOD catalog-related research.

Another issue to consider is the public understanding of catalog size and diversity. To what extent are audiences aware of these issues? How is knowledge about digital media services circulated and discursively framed in different countries (Lobato and Meese 2016)? Through what discourses_-such as access, choice, or dis/advantageare these issues being debated?

For example, one of the striking features of the Netflix rollout over the last six years is the amount of cross-country comparison and complaint it has generated among TV buffs in different parts of the world. In my own country, Australia, widespread complaints about the perceived small size and poor quality of the local catalog have been fueled by unofficial data from bloggers, app developers, unblocking services, and various other sources that rank and compared the offerings of the Australian catalog vis-à-vis the American service, revealing its apparent deficiencies. Articles based on this research then appear in mainstream newspapers (Grubb 2015; White 2015) and technology websites (Kidman 2015), feeding back into mainstream media coverage. In this way, a cycle of "Netflix knowledge" is created, based mostly on unofficial sources. Australia is not a unique case: similar comparisons and discussions take place in Canada (Edwards and Eastwood 2015), New Zealand (Bache 2015, cited in Stewart 2016), and Mexico (Castañares 2016), to name a few countries. ${ }^{7}$ (See Stewart 2016 for a fascinating discussion of the New Zealand case.)

All this suggests that SVOD catalogs are increasingly becoming objects of transnational comparison and contestation, in the sense that they crystallize wider anxieties about the direction, intensity, and origin of media flows, as well as concern about unequal access to television's "distribution revolution" (Curtin et al. 2014). The vernacular forms of research underpinning these debates are significant for media studies because they feed back into wider conversations about the relative power and privilege of different international markets, and how this power and privilege is spatially organized. As we have seen, much of this research relies on unofficial comparator sites and is therefore somewhat questionable. Nonetheless it draws our attention to a range of research possibilities that can be followed up by scholars in more conventional ways.

\section{Toward a Research Agenda for SVOD Catalogs}

In the examples discussed above, the outline of a larger research program on SVOD catalogs is emerging. Ranging from crude measures of catalog size to more sophisticated measures of the composition and diversity of SVOD programming, these examples illustrate how catalog data can be used to inform our understanding of digital distribution platforms and the content they make available to audiences.

The technical side of this research effort is evolving fast. Scraping tools are now widely used within media, communications, and Internet research (Bruns and Burgess 2016; Highfield and Leaver 2016), and a critical methodological literature has emerged to inform such projects (Hargittai and Sandvig 2015; Marres and Weltevrede 2013; Rogers 2013; Weller et al. 2013). There are opportunities here for TV research to 
Table I. A Netflix Research Agenda.

\begin{tabular}{|c|c|c|c|}
\hline \multicolumn{2}{|c|}{ Research question } & \multirow{2}{*}{$\begin{array}{l}\text { Relevant debate(s) } \\
\text { Viewer choice; media access } \\
\text { and (dis)advantage. }\end{array}$} & \multirow{2}{*}{$\begin{array}{l}\text { Data source and analytic technique } \\
\text { Catalog size comparison, via } \\
\text { automated scraping or comparator } \\
\text { site }\end{array}$} \\
\hline I. & $\begin{array}{l}\text { How big is the Netflix catalog } \\
\text { in each country? }\end{array}$ & & \\
\hline 2. & $\begin{array}{l}\text { How much local content is } \\
\text { included in each catalog? }\end{array}$ & $\begin{array}{l}\text { Cultural imperialism; } \\
\text { localization strategy }\end{array}$ & $\begin{array}{l}\text { Manual or automated coding of catalog } \\
\text { content, cross-referenced with other } \\
\text { production databases listing country } \\
\text { of origin }\end{array}$ \\
\hline 3. & $\begin{array}{l}\text { How much content is being } \\
\text { translated-and into which } \\
\text { languages? }\end{array}$ & $\begin{array}{l}\text { Linguistic diversity; cultural } \\
\text { imperialism }\end{array}$ & Language availability metadata \\
\hline 4. & $\begin{array}{l}\text { How does the content of each } \\
\text { catalog change over time? }\end{array}$ & $\begin{array}{l}\text { Political economy of } \\
\text { distribution: licensing } \\
\text { trends, supply-side } \\
\text { concentration/competition }\end{array}$ & $\begin{array}{l}\text { Scraping and analysis of catalog data, } \\
\text { repeated at intervals }\end{array}$ \\
\hline 5. & $\begin{array}{l}\text { Which content types are } \\
\text { represented, and to what } \\
\text { degree, in each national } \\
\text { catalog? }\end{array}$ & $\begin{array}{l}\text { Localization strategy; } \\
\text { market-culture interactions; } \\
\text { (possibly) national politics } \\
\text { of taste. }\end{array}$ & $\begin{array}{l}\text { Manual or automated coding based on } \\
\text { genre metadata and other attributes }\end{array}$ \\
\hline 6. & $\begin{array}{l}\text { What kinds of content are } \\
\text { most widely/narrowly available } \\
\text { across all Netflix services? }\end{array}$ & $\begin{array}{l}\text { Cultural diversity; cultural } \\
\text { imperialism; structure of } \\
\text { licensing deals }\end{array}$ & $\begin{array}{l}\text { Assemble master database (cumulative } \\
\text { titles) from national catalog scraping }\end{array}$ \\
\hline 7. & $\begin{array}{l}\text { What is the mix of new- } \\
\text { release and back-catalog } \\
\text { material in each Netflix } \\
\text { catalog? }\end{array}$ & $\begin{array}{l}\text { Long tail debates; portfolio } \\
\text { models; localization strategy }\end{array}$ & Year of production metadata \\
\hline 8. & $\begin{array}{l}\text { How much content is } \\
\text { being censored in different } \\
\text { countries? }\end{array}$ & $\begin{array}{l}\text { Censorship, regulation, } \\
\text { freedom of speech }\end{array}$ & $\begin{array}{l}\text { Compare duration of viewables across } \\
\text { markets to identify edited versions, } \\
\text { then manually inspect }\end{array}$ \\
\hline 9. & $\begin{array}{l}\text { How is the Netflix genre } \\
\text { taxonomy being applied to } \\
\text { global content? }\end{array}$ & $\begin{array}{l}\text { Distribution practices for } \\
\text { foreign content; cultural } \\
\text { competency of Netflix; } \\
\text { genrification }\end{array}$ & $\begin{array}{l}\text { Manual or automated coding based on } \\
\text { genre metadata }\end{array}$ \\
\hline 10. & $\begin{array}{l}\text { How are marketing materials } \\
\text { for Netflix originals being } \\
\text { customized in different } \\
\text { markets? }\end{array}$ & $\begin{array}{l}\text { Automation of distribution/ } \\
\text { marketing processes; } \\
\text { dynamics of localization; } \\
\text { national politics of taste }\end{array}$ & $\begin{array}{l}\text { Analysis of display images for Netflix } \\
\text { originals in selected catalogs }\end{array}$ \\
\hline
\end{tabular}

expand its methodological tool kit by borrowing ideas from these disciplines. At the same time, we also need to articulate these lines of inquiry to longer traditions of analysis to ensure that future research on Netflix and other SVOD platforms builds on what is already known about international audiovisual flows, without trying to reinvent the wheel. So we need good, critical questions, as well as the latest tools.

To this end, I have included a list of indicative research questions in Table 1, to show the range of issues that can be addressed through catalog research. Each of these questions is linked to a set of debates in media studies, and can be investigated empirically through particular kinds of data and metadata from the Netflix platform.

The purpose of listing these questions, methods, and debates together is precisely to show that, even when we are using new online sources, research of this nature can still usefully engage with old questions in media and communication studies about the direction and intensity of audiovisual flows. 
These are just a few of the research questions that can be asked of Netflix, and they gesture toward a larger set of potentially productive interactions between TV flows research and Internet research. Some of these questions are easy to answer (e.g., cata$\log$ size). Others are more difficult (anything to do with Netflix's genre taxonomy). A few are speculative in nature (e.g., the censorship question is enticing but would have to be tested in practice). Questions toward the end of the list also require analysis of the algorithmic filtering and personalization systems used by Netflix. My point here is that all of these questions have intellectual significance for television studies, because they relate directly to ongoing and unresolved debates in our field. From this perspective, we can see Netflix not only as another object of study but also as a vehicle for refining the television studies theory base.

A priority area for further research should be translation. Audiovisual translation, its processes, and its politics have long been underresearched topics in Anglophone screen studies. The structure of Netflix means that compiling detailed information about the amount of translated material in each catalog (including the target and origin languages) is relatively straightforward: the audio and subtitle metadata attached to each viewable contain such information, and this can be collected and compared between countries. We can then start to measure the dominant origin and target languages, as well as taking into account other nuances (such as the language of the Netflix interface). Such research may result in a stronger understanding of what SVOD means for the ongoing debates about cultural and linguistic diversity in the Internet age.

Some of the questions in Table 1 may seem very technical. But they are all fundamentally about culture and consumption. As an example, consider the question about marketing materials. Netflix's platform now customizes the promo images of each viewable using $\mathrm{A} / \mathrm{B}$ testing, so that it can track which images get the most clicks in different markets (Netflix 2016b). Comparison of international movie marketing campaigns is now a common method within screen distribution, marketing, and localization research (e.g. Mingant, Tirtaine, and Augros 2015), because it provides unique insights into how distributors understand particular territorial markets. Netflix is a rich resource for collecting this kind of data.

As a further example, consider question 10 about year of production. Measuring the age of viewables can help us to understand the ratio of new to old content, which has technical applications in media-economics research on portfolio and bundling strategy (Hiller 2016); but just as importantly, such data may help us to refine existing theories of cultural consumption and cultural distribution. For example, we could use this knowledge to inform an analysis of whether the long tail theory and its arguments about back-catalog content-famously developed with reference to Netflix's DVD library (Anderson 2006) - still hold water.

The possibilities for genre study via Netflix are also very rich. One dimension of this, which is already underway (Madrigal 2014; Smith-Rowsey 2016), involves attention to Netflix's unique genre taxonomy, especially its signature microgenres such as "Visually-Striking Foreign Nostalgic Dramas" (though of course we must ask, Foreign to whom?). Such work would be interesting to develop in a more international frame, 
given that we know little about how the Netflix taxonomy is developed and articulated across content being licensed from its newer international partners. Do Turkish soaps receive the same exhaustive generic characterization as U.S. indie comedies? What new microgenres might emerge when Netflix expands its taxonomies to include more non-U.S. content?

Beyond the question of genre taxonomies, there is also the question of how Netflix is bound up in wider processes of genrification (Altman 1999), or the historical and institutional construction of genre between industry and audiences. To this end, research could also explore the prevalence and currency of particular generic discourses ("quality Netflix drama," "binge-worthy series") in particular countries and how this articulates both with the social contexts of TV viewing in those countries and the contents of its Netflix catalog.

\section{Don'ts and Be Carefuls}

There are obvious risks when using catalogs as data sources. In addition to the technical challenges inherent in scraping any digital platform (Shumate and Weber 2015), we should also bear in mind the following issues when planning a Netflix research project.

\section{The Catalog Is Not the Audience}

Catalogs cannot, by definition, tell us anything about audience activity. Without access to the Netflix black box, we will never be able to understand what items audiences are actually watching, only the range of content provided to them. A catalog is therefore absolutely not a reliable indicator of taste, consumption, or demand within a given nation. It cannot be used as a proxy for the audience itself. ${ }^{8}$ The proper role of catalog analysis is to help us understand patterns of distribution, not reception.

\section{Filtering and Recommendation Adds Complexity}

Netflix users do not experience the catalog as a static list or schedule, but rather as a series of interactive, personalized recommendations that are algorithmically sorted according to user viewing history, demographic and location data. The catalog is the raw inventory of material from which these choices are automatically made, and is important to study for this reason, but it will be rarely visible to users as a catalog. Most users will experience only the fragments of it that are pushed forward to them algorithmically, through Netflix's "complex alchemy of audiovisual matchmaking" (Hallinan and Striphas 2016, 117).

\section{The Catalog Is a "Market-Image," at Best}

Although Netflix catalogs do not tell us anything straightforward about what kind of media are preferred in different nations, they can tell us something about what Netflix 
thinks certain nations might enjoy. In other words, Netflix data are useful as a firstorder resource indexing content availability across a global platform, as well as a second-order resource that tells a story about the strategic rationalities underpinning Netflix's internationalization. It does not provide any meaningful insight into the actual preferences of audiences. Note also that the market-image only applies to strategically important markets where Netflix has invested resources into understanding and catering to what it sees as the preferences of that market, and building those preferences into its catalog through local content licensing deals. So we must be careful about divining intentionality here.

\section{Netflix Caters to Different Niches in Different Countries}

A limitation of single-platform research is that it can only tell us about the media environment in one particular distribution system (Netflix), which of course is only a small part of any national media ecology (Hargittai 2015). This is complicated further by the fact that both the number of users in each country and their social demographics are extremely variable. ${ }^{9}$ In the United States, Netflix is a mainstream middle-class product, but in other parts of the world its use is either negligible or limited to cosmopolitan upper-classes whose tastes may not be indicative of their fellow citizens. (The company has publicly stated that it targets "English language-speaking elites" in foreign markets [Netflix 2016a].) In other words, comparison of Netflix catalogs can be fraught because they cater to different kinds of global users, not just to different national markets. In some cases, Netflix catalogs might be better understood through the prism of transnational class formations rather than the frame of the national audience.

So, there are a lot of potential problems to consider, but also many opportunities. Let me conclude by underscoring a key point arising from the previous discussion. Netflix is new, fast-evolving, and complicated; it is a black box, governed by algorithms and automation. But this does not mean that the existing repertoires of media research no longer work, nor that we have to develop entirely new paradigms of analysis. In showing how Netflix catalog data can be used to understand cross-border media flows, I have tried to make a case from a combination of the new and the old in media research. As a hybrid system combining television, cinema, and Internet technologies, Netflix is naturally responsive to the emergent digital methods such as scraping and big data analytics, but its international catalog system can also be studied in relation to legacy media studies questions - questions about cross-border media flows, global/ local dynamics, and audiovisual diversity. In other words, Netflix provides an opportunity to extend existing traditions of global television research, and to further debate the critical questions that they have put on the agenda.

\section{Acknowledgment}

Many thanks to Karen Horsley, Tessa Dwyer, Amanda Lotz and Nic Suzor for their valuable input into this article. 


\section{Declaration of Conflicting Interests}

The author declared no potential conflicts of interest with respect to the research, authorship, and/or publication of this article.

\section{Funding}

The author disclosed receipt of the following financial support for the research, authorship, and/or publication of this article: This research is supported by the Australian government through the Australian Research Council's Discovery Early Career Award scheme (project DE150100288).

\section{Notes}

1. It is important to distinguish catalogs from libraries. In the Hollywood lexicon, a library is a suite of content assets owned by a particular media company or institution (Hoyt 2014). Although library and catalog are interchangeable in everyday usage (and are used interchangeably on the Netflix website), for our purposes, "library" involves longterm ownership by a rightsholder, while "catalog" involves shorter-term licensing by a platform.

2. Nordenstreng and Varis (1974) used a questionnaire to ask TV broadcasters around the world about their programming, and supplemented this with their own analysis of publicly available TV schedules.

3. Scholars including Napoli (1999) and Webster (2006) revised these content diversity methods by emphasizing other metrics, such as exposure diversity (what audiences actually watch, rather than what is programmed for them).

4. European Union proposals for a minimum European content quota are now well advanced, as discussed later in this article.

5. A similar scrape performed a year earlier (Simpson 2016) produced a different list, with Canada, Latin American countries, and the United Kingdom rounding out the top ten after the United States, instead of Caribbean countries.

6. Unofficial Netflix comparator sites were used as data sources. In the 2015 report, Allflix was used; in the 2016 report, Unogs was used.

7. A second strand of research involves counting and comparing the size of catalogs across competing services, often focusing on Netflix versus Amazon. For example, CNBC used data from the Instantwatcher comparator app to compare Amazon and Netflix on the basis of both size and "quality," using user star ratings as a proxy (Fahey 2016). Variety has also used data from Instantwatcher in a similar way (Spangler 2016; cf. Carr 2012).

8. It may be possible to use user-submitted ratings and reviews as a proxy for audience engagement, but this approach is problematic because audiences do not post information in a uniform, predictable, or representative manner. In 2017, Netflix removed star ratings completely, replacing them with thumbs-up and thumbs-down icons.

9. Netflix does not release country-by-country breakdowns of its subscriber base, only cumulative global and U.S. figures. In the absence of territory-specific data, financial analysts such as IHS Markit provide their own estimates. It is also possible to guess at the distribution of Netflix subscribers - in very rough terms - by looking at the company's network infrastructure (Böttger et al. 2016). 


\section{References}

Altman, Rick. 1999. Film/Genre. London: British Film Institute.

Anderson, Chris. 2006. The Long Tail: Why the Future of Business Is Selling Less of More. New York: Hyperion.

Bache, Rachel. 2015. “America's Netflix Library Is So Much Bigger than Ours.” New Zealand Herald, July 8. http://www.nzherald.co.nz/entertainment/news/article.cfm?c_id=1501119 \&objectid $=11477552$.

Böttger, Timm, Felix Cuadrado, Gareth Tyson, Ignacio Castro, and Steve Uhlig. 2016. "Open Connect Everywhere: A Glimpse at the Internet Ecosystem through the Lens of the Netflix CDN." ARXIV Working Paper. https://arxiv.org/abs/1606.05519.

Bruns, Axel, and Jean Burgess. 2016. "Methodological Innovation in Precarious Spaces: The Case of Twitter." In Digital Methods for Social Science, edited by Steven Roberts, Helene Snee, Christine Hine, Yvette Morey, and Hayley Watson, 17-33. Basingstoke: Palgrave.

Carr, Austin. 2012. "Amazon Massively Inflates Its Streaming Library Size." Fast Company, April 12. https://www.fastcompany.com/1830524/amazon-massively-inflates-its-streaming-library-size.

Castañares, Itzel. 2016. "Netflix ofrece más contenido en México que en Japon o Chile" [Netflix offers more content in Mexico than in Japan or Chile]. El Financiero (Mexico), July 12. http://www.elfinanciero.com.mx/empresas/netflix-ofrece-mas-contenido-en-mexico-queen-japon-o-chile.html.

Curtin, Michael, Jennifer Holt, and Kevin Sanson, eds. 2014. Distribution Revolution: Conversations about the Digital Future of Film and Television. Berkeley: University of California Press.

Edwards, Peter, and Joel Eastwood. 2015. "The List Netflix Doesn't Want You to See: How Canada Really Stacks Up to U.S. Version.” Toronto Star, January 22. https://www.thestar. com/entertainment/2015/01/22/the-list-netflix-doesnt-want-you-to-see-how-canada-reallystacks-up-to-us-version.html.

Ene, Laura, and Christian Grece. 2015. Origin of Films in VOD Catalogs in the EU. Strasbourg: European Audiovisual Observatory.

Fahey, Mark. 2016. "Netflix vs. Amazon: Estimating the Better Deal." CNBC.com, April 22. http://www.cnbc.com/2016/04/22/netflix-vs-amazon-estimating-the-better-deal.html.

Fontaine, Gilles, and Christian Grece. 2016. Origin of Films and TV Content in VOD Catalogues in the EU \& Visibility of Films on VOD Services. Strasbourg: European Audiovisual Observatory.

Grubb, Ben. 2015. "How the Australian Netflix Differs from the U.S. Service." The Age, March 24. http://www.smh.com.au/digital-life/hometech/how-the-australian-netflix-differs-fromthe-us-service-20150323-1m60g8.html.

Hallinan, Blake, and Ted Striphas. 2016. "Recommended for You: The Netflix Prize and the Production of Algorithmic Culture." New Media \& Society 18 (1): 117-37.

Hargittai, Eszter. 2015. "Is Bigger Always Better? Potential Biases of Big Data Derived from Social Network Sites." The ANNALS of the American Academy of Political and Social Science 659:63-76.

Hargittai, Eszter, and Christian Sandvig, eds. 2015. Digital Research Confidential: The Secrets of Studying Behavior Online. Cambridge: MIT Press.

Highfield, Tim, and Tama Leaver. 2016. "Instagrammatics and Digital Methods: Studying Visual Social Media, from Selfies and GIFs to Memes and Emoji." Communication Research and Practice 2 (1): 47-62. 
Hiller, R. Scott. 2016. "Profitably Bundling Information Goods: Evidence from the Evolving Video Library of Netflix." SSRN Working Paper. http://ssrn.com/abstract=2638101.

Hoyt, Eric. 2014. Hollywood Vault: Film Libraries before Home Video. Berkeley: University of California Press.

Katz, Elihu, and George Wedell. 1978. Broadcasting in the Third World: Promise and Performance. Cambridge: Harvard University Press.

Kidman, Angus. 2015. "These Are the Most Popular Movies Netflix Australia is Missing." Lifehacker, March 24. http://www.lifehacker.com.au/2015/03/these-are-the-most-popularmovies-netflix-australia-is-missing/.

Liebes, Tamar, and Elihu Katz. 1990. The Export of Meaning: Cross-Cultural Readings of "Dallas." New York: Oxford University Press.

Litman, Barry. 1979. "The Television Networks, Competition and Program Diversity." Journal of Broadcasting 23 (4): 393-410.

Lobato, Ramon, and James Meese, eds. 2016. Geoblocking and Global Video Culture. Amsterdam: Institute of Network Cultures.

Lotz, Amanda. 2014. The Television Will Be Revolutionized, 2nd Edition. New York: New York University Press.

Lotz, Amanda. 2017. Portals: A Treatise on Internet-Distributed Television. Ann Arbor: University of Michigan Press.

Madrigal, Alexis. 2014. "How Netflix Reverse Engineered Hollywood." The Atlantic, January 2. http://www.theatlantic.com/technology/archive/2014/01/how-netflix-reverse-engineeredhollywood/282679/.

Marres, Noortje, and Esther Weltevrede. 2013. "Scraping the Social? Issues in Live Social Research." Journal of Cultural Economy 6 (3): 1-23.

Mingant, Nolwenn, Cecilia Tirtaine, and Joël Augros. 2015. Film Marketing into the TwentyFirst Century. London: British Film Institute.

Napoli, Phliip M. 1999. "Deconstructing the Diversity Principle." Journal of Communication 49 (4): 7-34.

Netflix. 2016a. "Q1 Earnings Interview." Video, April 18. https://www.youtube.com/ watch? $\mathrm{v}=5 \mathrm{wAlIVtgBz} 0$.

Netflix. 2016b. "The Power of a Picture." Press release, May 3. https://media.netflix.com/en/ company-blog/the-power-of-a-picture.

Nordenstreng, Kaarle, and Tapio Varis. 1974. Television Traffic-A One-Way Street? A Survey and Analysis of the International Flow of Television Programme Material. Reports and Papers on Mass Communication. Paris: UNESCO.

Peter H. Miller, and Randal Rudniski. 2012. "Market Impact and Indicators of Over the Top Television in Canada: 2012." Ottawa: Canadian Radio-television and Telecommunications Commission. http://www.crtc.gc.ca/eng/publications/reports/rp120330.htm.

Rogers, Richard. 2013. Digital Methods. Cambridge: MIT Press.

Sedgwick, John. 2000. Popular Filmgoing in 1930s Britain: A Choice of Pleasures. Exeter: Exeter University Press.

Shumate, Michelle, and Matthew S. Weber. 2015. "The Art of Web Crawling for Social Research.” In Digital Research Confidential: The Secrets of Studying Behavior Online, edited by Esther Hargittai and Christian Sandvig, 201-22. Cambridge: MIT Press.

Simpson, Campbell. 2016. "Netflix's Movie Libraries in Every Major Country, Compared." Gizmodo, January 15. http://www.gizmodo.com.au/2016/01/netflixs-movie-libraries-inevery-major-country-compared. 
Sinclair, John, Liz Jacka, and Stuart Cunningham. 1995. New Patterns in Global Television: Peripheral Vision. New York: Oxford University Press.

Smith-Rowsey, Daniel. 2016. "Imaginative Indices and Deceptive Domains: How Netflix's Categories and Genres Redefine the Long Tail." In The Netflix Effect: Technology and Entertainment in the 21st Century, edited by Kevin McDonald and Daniel Smith-Rowsey, 63-80. New York: Bloomsbury Academic.

Spangler, Todd. 2016. “Amazon Prime Video Has 4 Times Netflix's Movie Lineup, But Size Isn't Everything." Variety, 22 April. http://variety.com/2016/digital/news/netflix-amazonprime-video-movies-tv-comparison-1201759030/

Stewart, Mark. 2016. "The Myth of Televisual Ubiquity." Television \& New Media 17 (8): 691-705.

Tryon, Chuck. 2013. On-Demand Culture: Digital Delivery and the Future of Movies. New Brunswick: Rutgers University Press.

Veed Analytics. 2016. "Old Wine in New Bottles: Originals." Veed Snapshot research report. München: Veed Video Services Intelligence.

Verhoeven, Deb, Bronwyn Coate, Stuart Palmer, and Colin Arrowsmith. 2016. "Using Big Cultural Data to Understand Diversity and Reciprocity in the Global Flow of Contemporary Cinema." Working Paper. http://dro.deakin.edu.au/view/DU:30091474.

Webster, James G. 2006. "Diversity of Exposure." In Media Diversity and Localism: Meaning and Metrics, edited by Philip M. Napoli, 309-25. Mahwah: Lawrence Erlbaum.

Weller, Katrin, Axel Bruns, Jean Elizabeth Burgess, Cornelius Puschmann, and Merja Mahrt, eds. 2013. Twitter and Society. New York: Peter Lang.

White, Dominic. 2015. "Stan, Netflix Lead in Volume of Video Streaming Content on Offer." Sydney Morning Herald, April 22. http://www.smh.com.au/business/media-and-marketing/ stan-netflix-lead-in-volume-of-video-streaming-content-on-offer-20150422-1 mqhn1.html.

Williams, Raymond. (1974) 2003. Television: Technology and Cultural Form. Abingdon: Routledge Classics.

\section{Author Biography}

Ramon Lobato is Senior Research Fellow in the School of Media and Communication at RMIT University. He has published widely on screen distribution, copyright, and piracy. His books include Shadow Economies of Cinema (BFI 2012), The Informal Media Economy (Polity 2015, with J. Thomas), and Geoblocking and Global Video Culture (INC 2016, ed., with J. Meese). 